\title{
Towards an holistic approach to energy access in humanitarian settings: the SET4food project from technology transfer to knowledge sharing
}

\author{
Jacopo Barbieri ${ }^{1 *}$, Fabrizio Leonforte ${ }^{2}$ and Emanuela Colombo ${ }^{1}$
}

\begin{abstract}
The increasing number of displaced people in the world not only requires rapid humanitarian actions, but also attention to host communities and a holistic and long-term vision. Energy has not been really considered a major topic in people displacement, yet, resulting in negative impacts on several aspects, including food security. New solutions are required, in terms of energy planning, technology development, and adaptation, as well as decision making, sensitization, training, and support to humanitarian actors. The Sustainable Energy Technologies for food security (SET4food) project phase 1 (2014-2015) developed a number of tools to support identification, adaptation, and introduction of appropriate solutions, tested some pilot innovations in critical areas, and promoted the enhancement of humanitarian response capability in the energy sector via an extensive capacity building program. In addition, a second phase of the project (2015-2018) fostered networking and collaboration between the main actors by developing an e-sharing platform, called ENERGYCoP, including a global not-for-profit community of practices for humanitarian professionals working in the energy sector. The platform may enable the shift from traditional "technological transfer" to a more participative approach on co-design and technological cooperation activated by a knowledge sharing mechanism. This paper outlines the main challenges and the achieved results of SET4food, providing recommendations for researchers and practitioners on the way forward.
\end{abstract}

Keywords: Energy access, Energy planning, Knowledge transfer, Humanitarian settings

\section{Introduction}

In 2018 about 135 million people will need humanitarian assistance to survive (OCHA 2017). This estimate represents the highest value since the Second World War and has been constantly rising in the last period. The number of forcibly displaced people has grown from 33.9 million in 1997 to 65.6 million in 2016, and it has been substantially increasing in particular during the last 6 years (UNHCR 2016). Insufficient level of food security represents one of the most relevant concerns for such people, which is often linked to insufficient access to energy, especially when looking at food utilization. According to the Office for the Coordination of Humanitarian Affairs (OCHA), "Energy insecurity may also drive food insecurity. Without access to a predictable energy supply,

\footnotetext{
* Correspondence: jacopo.barbieri@polimi.it

'Department of Energy, Politecnico di Milano, Milan, Italy

Full list of author information is available at the end of the article
}

communities that are not food insecure may become so, and those who are already food-insecure may become even more vulnerable. There can be no food security for communities without reliable access to a fuel source for heating and cooking" (OCHA 2010). Unfortunately, access to energy in emergency and humanitarian settings is often critical and entails five key challenges: "protection, relations between hosts and displaced people, environmental problems, household energy-related natural resource restrictions, and livelihood-related challenges" (Lyytinen 2009; Barbieri et al. 2017). Appropriate technologies for cooking, food preservation, and water purification are necessary to ensure an effective and efficient food utilization, which also requires a sufficient level of access to energy and fuels. The provision of appropriate energy services can contribute substantially to increase opportunities for refugees and internally displaced persons (IDPs) and help them to lead a more productive and active life (Bellanca 2014). 
At the institutional level, the general relevance of access to energy in many aspects of people's life and in human promotion has been pointed out by the Sustainable Energy for All (SE4All) Initiative and lead to Goal 7 into the Agenda 2030, even if an explicit reference to humanitarian settings misses. On the other hand, the Safe Access to Fuel and Energy (SAFE) was the first body focusing the attention on crisis-affected populations, in particular refugees and IDPs (WFP 2015). Later on, many organizations declared the importance of energy in humanitarian and development in several documents (FAO 2015; Türk et al. 2015; SAFE 2016).

The Moving Energy Initiative (MEI) is the first international partnership focusing more on the multifaceted role of energy for displaced people, stressing the attention on the need to develop an alternative way of dealing with camps and change common perception about them. In fact, better practices on energy use are strongly needed in humanitarian settings, considering that current ones are economically, environmentally, and socially unsustainable, since they generate depletion of natural resources and pollution, negative impacts on people health and security, social disparity, huge costs, and potential social conflicts among people (Lahn and Grafham 2015; Gunning 2014). Barriers to this energy shift are not only technological, but also institutional, operational, and political. Moreover, "a severe shortage of energy expertise in the humanitarian system and no systematic approach to planning for and managing energy provision" are among the key elements (Lahn and Grafham 2015).

In the last few years, different projects looked at how to introduce innovations to maximize efficiency and minimize environmental impact. Such projects have been carried out by SAFE and other actors. However, many of them have failed for different reasons or have not been scaled up (Aste et al. 2016; Barbieri et al. 2017).

This work aims at describing the rationale, objectives, and main activities of the Sustainable Energy Technologies for food security in humanitarian contexts (SET4food) project in order to increase the chances to capitalize its findings and experience and to share with the scientific community a potential way forward, starting from a better response.

\section{A comprehensive approach towards better response}

Based on the previous analysis, there are different components which can be improved in order to achieve the goal of enhancing the capacity of the humanitarian sector in ensuring the provision of safe energy access in critical contexts.

In particular, focusing on capability elements related to energy and to the energy-food nexus, the humanitarian sector lacks the following (Jenks et al. 2018; Callaghy and Riddley 2018; Rosemberg-Jansen 2018; Puri et al. 2017):

1. Knowledge and awareness of energy relevance: humanitarian actors have little awareness and knowledge of the importance of alternative energy options, especially but not exclusively about food security (in particular food utilization);

2. Capacity in planning, implementation, monitoring, and evaluation: humanitarian actors have limited technical capacity and supportive tools to identify, design, and implement appropriate energy solutions, both at the HQ and field levels. Methodologies to collect, share, and analyze data about access and use of energy are not well-known and standardized, thus evidences and reliable data are not easily available. Similar considerations also apply to monitoring and evaluation (M\&E) procedures and impact evaluation frameworks specific to energy projects;

3. Coordination: despite the effort of SAFE and its members, the humanitarian system is scarcely coordinated about energy-related issues, at the local and global levels. Information sharing among actors from different sectors, including private companies and research centers is limited as well, especially on issues related to people displacement or emergency.

The SET4food project tried to address such problems in two phases. The first one was implemented in 2014-2015 with the aim of improving the response capacity of humanitarian actors in identifying and implementing efficient and sustainable energy technologies, in particular for food utilization. All the activities aimed at contributing to make energy utilization more efficient and sustainable. The main project beneficiaries were humanitarian actors (operators and organizations), in order to make them more effective to support food security among refugees and IDPs. The second phase of SET4food, developed between May 2016 and April 2018, aimed to expand the previous one, not only enhancing the capacity of the single actors, but also promoting coordination and collaboration among them.

Thus, SET4food phases 1 and 2 have been designed including the following main components which respond to the three criticalities:

1. Training and capacity building Training and capacity building on energy topics have been delivered both in-presence and online to enhance knowledge and awareness of energy relevance. 
2. Energy planning methodology, pilot testing, and supportive tools

2.a. Development of a methodology for energy planning, technology transfer, and adaptation;

2.b.Implementation of pilot projects in Central African Republic (CAR), Haiti, Lebanon, and Somalia in order to test the methodology and propose innovative, integrated energy solutions for cooking, food preservation, water purification, and lighting.

2.c. Development of supportive tools: a package of tools for decision making and project implementation was created. It is composed by (i) the SET4food Guidelines on sustainable energy technologies for food utilization in humanitarian contexts and informal settlements (SET4food Guidelines); (ii) the Decision Support System (DSS) for preliminary identification of a ranking of potentially appropriate energy solutions; (iii) the impact evaluation framework interactive tool; (iv) the guidelines on $M \& E$ (monitoring and evaluation) of energy projects.

3. Networking and knowledge sharing

The Energy Community of Practices $(\text { ENERGYCoP) })^{1}$ is the virtual platform created by SET4food, where actors from different sectors can share information about energy, and improve networking and collaboration.

\section{SET4food main project's components}

The different project's components are detailed in the following sections, in order to highlight the way in which the project tackles the emerged criticalities.

\section{Training and capacity building}

In-presence and online trainings were set up within the SET4food action in order to increase the awareness on energy-related problems among humanitarian operators and to provide them with a sufficient background in order to face the challenge of safe energy provision in emergency and post-emergency situations.

The e-learning course Appropriate energy technologies for food utilization in refugee camps and informal settlements: overview, selected criteria, and pilot case studies was created and disseminated. It is based on the experience gained from the field pilots and from the development of the SET4food Guidelines. It introduces the linkages between energy technologies and food utilization (food preparation and preservation) in humanitarian contexts. The course is organized in five modules, each one focusing on a different aspect ${ }^{2}$ :
- Module 1-Access to sustainable energy as leverage to development and human rights' enjoyment;

- Module 2-Access to energy in refugee/IDP camps and informal settlements;

- Module 3-Energy and food in refugee/IDP camps and informal settlements;

- Module 4-Energy technologies for food preparation and conservation;

- Module 5-Identification of appropriate technologies for preparation and preservation: the SET4food decision support system (DSS).

In-presence intensive courses were also carried out in the framework of Master courses in Development and Cooperation in Colombia, Italy, Kenya, Nepal, and Palestine during the first phase of the project. Although the workshops mainly addressed the students of the master, they were also open to humanitarian actors, academic staff, local authorities, and private companies. They allowed to add further details compared to the online course and to interact with international experts.

Moreover, during the second phase, a further in-presence training has been delivered in Milano (Italy) to about 20 persons. The training was designed for professionals already involved in the humanitarian and development sectors, with the aim of strengthening the response capacity of humanitarian actors in the energy sector. Through a participatory methodology that included individual presentations and group works, participants shared experiences and best practices constantly supported by the trainers, who provided the necessary inputs to encourage constructive discussions and the development of innovative content.

\section{Methodology for energy planning, technology transfer, and adaptation}

The main objective of this project component was to propose a methodology for humanitarian actors to select and introduce in an effective way appropriate and innovative energy technologies for food utilization in temporary, quasi-permanent, permanent camps, or informal settlements.

In fact, depending on the context, a number of different solutions can arise, since local needs drive the selection. Moreover, in the same context, technology solutions selected by different teams can differ, due to the fact that innovation is a creative process, which involves people with different ideas and opinions. Different time constraints may also lead to different solutions. Based on such considerations, the work carried on at the beginning of the project allowed to define a preliminary methodology for energy planning, technology transfer, and adaptation. The methodology was then refined several times during both phases 1 and 2, based on the learnings from its implementation in the field (Aste et 


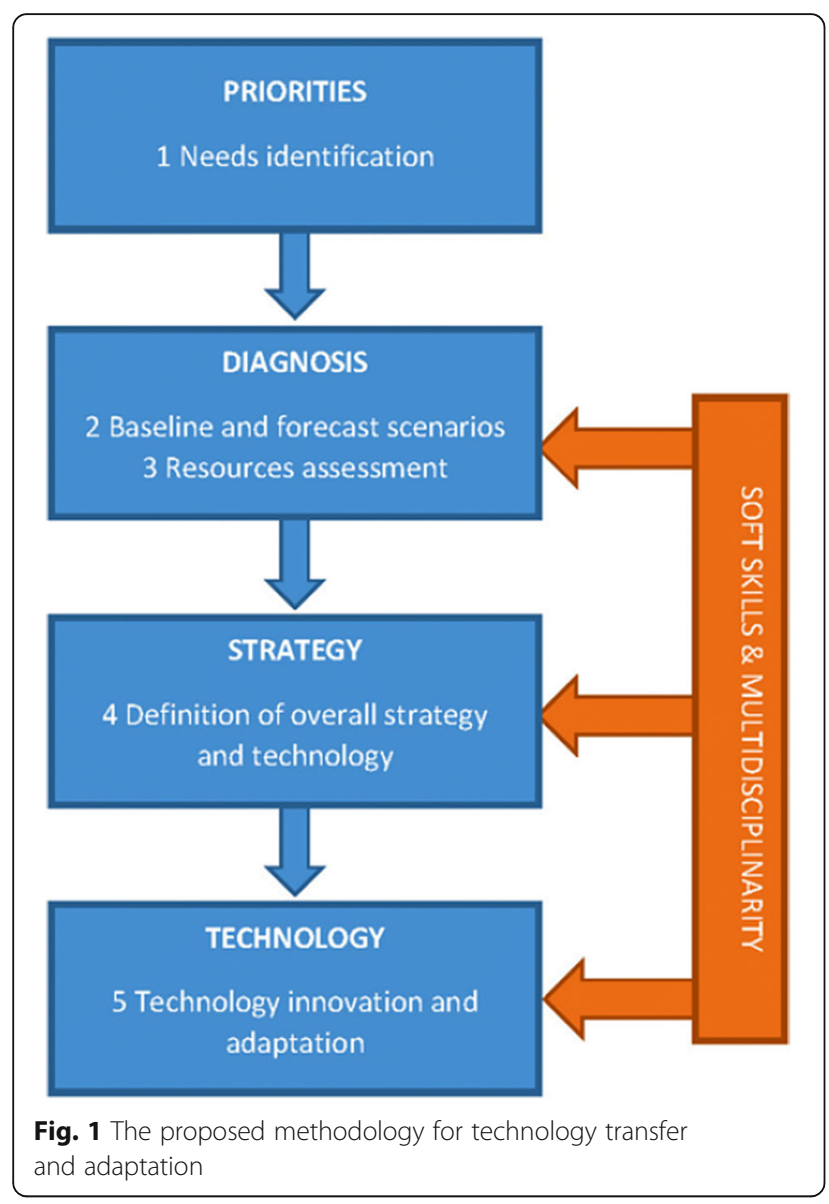

al. 2017). The final version is constituted by the following key steps (Fig. 1):

1. Priorities: in this phase the identification of basic needs is carried out. This allows to define priorities in the response. Priorities are identified according to the most relevant and most contingent needs of the local community in terms of (i) basic need for households, (ii) community services, and (possibly) (iii) productive activities. This step is carried out through the distribution of questionnaires to potential beneficiaries in order to get a specific assessment of local priorities and needs. Local staff have to be involved in the process of data collection, including interviewing, and in a preliminary debriefing. This in-depth analysis provides a first assessment of living conditions, challenges, barriers, and needs. This phase leads to define the main goals of the intervention.

2. Diagnosis: during the diagnosis phase, the energy demand is evaluated according to the needs. The amount of water, fuel consumptions, etc., defines the overall load to be met. Any constraint or vinculum given by the specific context is accounted, since this kind of elements can greatly affect the design of the solution (e.g., household-based vs community-based solutions). This phase leads to set the energy amounts necessary to satisfy priority needs and constraints that the technological solution needs to meet and respect.

3. Strategy: this phase drives the selection of the intervention strategy. In the SET4food's pilot projects, the strategy concerned the identification of the areas of intervention and the most appropriate technological scenarios. This phase leads to selecting the scope of intervention by coupling appropriate technologies with local needs and available financial resources.

4. Technology: during this step, a preliminary ranking of different technology layouts is defined, based on the results of the previous steps. In particular, different technologies having different characteristics are ranked based on the constraints and opportunities identified in the previous steps, such as traditional ways and habits of cooking, which may affect acceptability and adoption of new cooking systems; familiarity of beneficiaries with new technologies, which may affect the effectiveness of introducing sophisticated technologies for preserving food and purify water; availability and affordability of the spare parts in the local market, which may represent a threat to longterm sustainability. Based on the main constraints, a process of adaptation can be undertaken, in order to investigate whether an already existing solution may be modified to better match with local needs and habits. For example, an existing model of improved cooking stove may require adaptation in its dimensions in order to be usable with the pots already in place, or a commercial electric refrigerator may require modifications in order to guarantee its proper operation also during blackout periods. This phase leads to the definition of the final solution.

\section{Pilot projects}

The proposed methodology has been applied in pilot projects in four countries: Lebanon, Somalia, Central African Republic, and Haiti. Such pilots allowed to test the implementation of some technologies that are usually not considered in humanitarian contexts at the same time. This fact required significant adaptation of the technology itself in many cases. The pilots targeted different contexts, including refugees and IDPs in camps and informal settlements.

In order to show how the methodology was applied, Table 1 summarizes the information gained in each step for 
Table 1 Proposed methodology applied to a settlement in Lebanon

\begin{tabular}{|c|c|c|}
\hline Cooking & Electric power & Food preservation \\
\hline \multicolumn{3}{|l|}{ Phase 1-Priorities } \\
\hline \multicolumn{3}{|l|}{$\begin{array}{l}\text { Type of settlement: } \\
\text { Informal settlement } \\
\text { Housing structures: } \\
\text { (i) Multiple floors uncompleted cement } \\
\text { building } \\
\text { (ii) Tents surrounding the cement building }\end{array}$} \\
\hline $\begin{array}{l}\text { Need: } \\
\text { To decrease the costs for cooking and } \\
\text { improve comfort and safety of cookers }\end{array}$ & $\begin{array}{l}\text { Need: } \\
\text { (i) To have a reliable source of lighting for households } \\
\text { (ii) To guarantee the utilization of basic appliances such } \\
\text { as mobiles } \\
\text { (iii) To guarantee safety in common spaces }\end{array}$ & $\begin{array}{l}\text { Need: } \\
\text { To preserve fresh food and leftovers in a safe } \\
\text { way }\end{array}$ \\
\hline
\end{tabular}

Phase 2-Diagnosis

\section{Solutions in place:}

Gas burners coupled to bottled gas to cook dry and fresh food

Constraints and opportunities:

(i) Community and shared solutions are

accepted among relatives ${ }^{+}$

(ii) Cooking is performed independently

by each family at different times

(iii) People cook both outdoor and indoor

(iv) Gas stove components available in

the local market ${ }^{+}$

Estimated firepower:

4-6 kW per stove per family

\author{
Solutions in place: \\ (i) Illegal grid connection for few hours every day for the \\ tents \\ (ii) Legal connection for few hours every day for people \\ living in the building \\ Constraints and opportunities: \\ (i) Community and shared solutions, such as plugs in \\ common spaces, are accepted by people who live in the \\ building and in some tents ${ }^{+}$ \\ (ii) No measure available of the actual electricity \\ consumption \\ (iii) Wide range of electric technologies available in the \\ local market ${ }^{+}$ \\ (iv) Presence of local technicians having experience with \\ renewable energy systems ${ }^{+}$ \\ Estimated electric load: \\ (i) $0.2 \mathrm{kWh}$ /day per family with 2 LED bulb lamps and 2 \\ security lights \\ (ii) $0.5 \mathrm{kWh}$ /day per family with 2 LED bulb lamps, 2 \\ security lights, and a thermoelectric refrigerator \\ (iii) $2 \mathrm{kWh} /$ day in case of community refrigerator
}

Solutions in place:

None

Constraints and opportunities:

(i) Sharing of same technology in common

space is considered acceptable ${ }^{+}$

(ii) Sharing of the same space for food storage

(e.g., same compartment of same refrigerator) is

not acceptable

(iii) Fresh food is available in the market ${ }^{+}$

(iv) Refugees have already used food

preservation technologies in the past (refrigerators) ${ }^{+}$

Estimated quantity of food to be preserved:

Few kilograms per family

Phase 3-Strategy

The adopted strategy aims at improving the situation considering all the three identified dimensions (food cooking, food preservation, and electric power for basic needs), trying to propose an integrated response. The strategy includes the following actions:

(i) Provision of a technical solution to improve the efficiency, usability and safety of gas burners

(ii) Provision of an alternative power system to ensure the reliability of the electric service

(iii) Provision of a reliable and simple solution to preserve fresh food, based on refrigeration

Phase 4-Technology

Locally made pot skirts for gas burners made with metal sheets and provided with external insulation

Hybrid PV/wind micro-grid assembled starting from locally available devices, able to manage primary loads (refrigerators) and auxiliary loads (other loads) separately
Locally assembled community refrigerators (700 I), with additional thermal storage and multiple individual compartments

Factors with the symbol ${ }^{+}$were found as opportunities

the case of one settlement in Lebanon as an example, focusing on cooking, electric power, and food preservation. Firstly, during the priorities phase, the assessment allowed to identify the main characteristics of the context and the most important needs expressed by the refugees. As a second step, based on the analysis of such information, and on additional technical information collected by direct observation in the field, the energy requirements and the technical characteristics of the technologies already in use were determined, as well as any relevant constraints and opportunities that could affect new solutions, such as the availability of local technicians to install and repair the systems and the availability of components in the local market. As a third step, a strategy for the intervention was defined according to the overall depicted figure, which allowed to proceed with a final selection of the technologies and their adaptation to the local context (step 4).

As per implemented solutions, we summarize hereafter the most interesting ones, in terms of innovation in humanitarian contexts, discussing their characteristics, and the results in terms of acceptability and effectiveness of the proposed technology (refer to Additional file 1 for a summary of all the implemented solutions, with the level of success and the main lessons learned). 


\section{Pot skirt for gas burners (Lebanon)}

A pot skirt is a simple round piece of metal which is placed at the top of the combustion chamber where the flames are in contact with the bottom of the pot. It encloses the pot and forces the flame and hot gases to its sides (Wohlgemuth et al. 2009; Barbieri et al. 2015). Pot skirts are widely used to improve the performances of biomass improved cooking stoves (ICS), but their utilization is not common with gas burners. However, when applied to gas burners, pot skirts reduce the heat losses thus increasing the overall performances of the stoves and decreasing fuel consumption. The proposed artisanal model was specifically designed for the gas burners used in the settlements by the 13 families who lived in the place. The design improved safety of the burners by adding an external thermal shielding to avoid burns (Fig. 2 and Fig. 3).

The collection of quantitative data about fuel savings was prevented by the adverse conditions in the settlement; however, beneficiaries expressed a high appreciation of the technology, referring that gas cylinders could last longer and that cooking outside was made easier due to the fact that the flame is sheltered from the wind. All the families declared that they could better meet their energy needs due to the new technology. In fact, in most cases, pot skirts were used regularly by the families (in average, pot skirts have been used 5-6 times per week, based on a regular monitoring of all beneficiary families on a period of 7 months), without any particular problems in terms of usability. Thus, despite the fact that it was not possible to quantify the reduction of fuel consumption, the field testing showed a promising

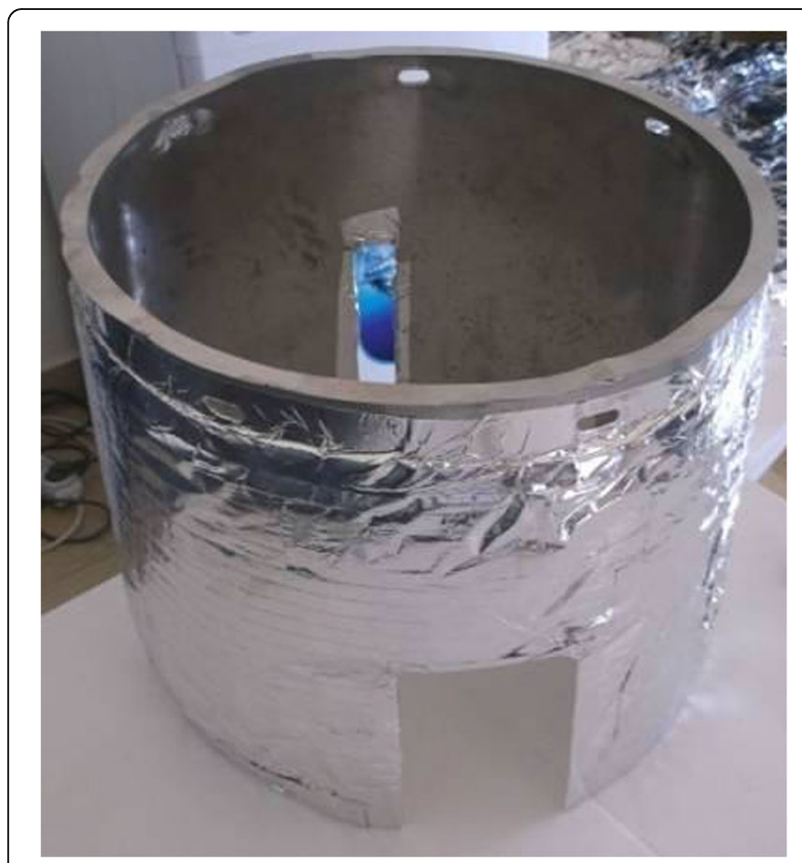

Fig. 2 Assembled SET4food pot skirt

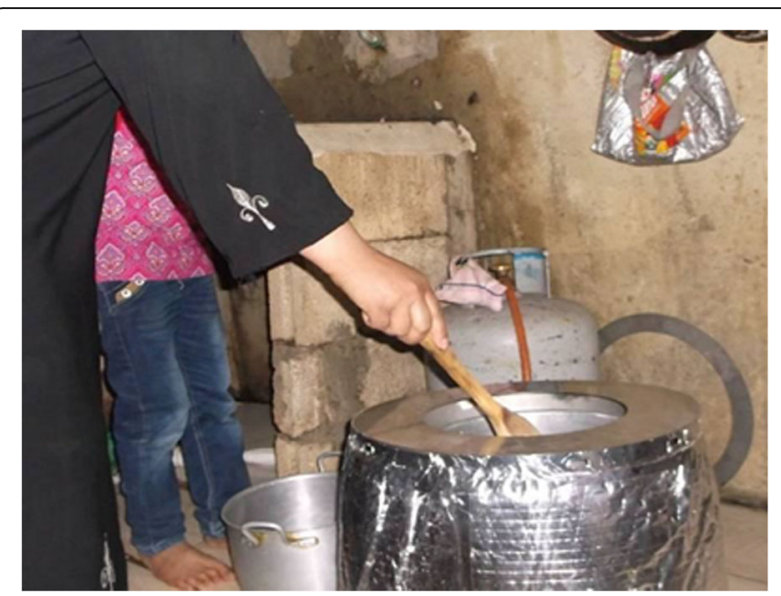

Fig. 3 Utilization of the SET4food pot skirt in a household in Lebanon

potential of this simple technology in critical contexts also when bottled gas is the main fuel.

\section{Standalone electric systems coupled with thermoelectric refrigerators (Lebanon)}

The solution consists in a simple photovoltaic DC system that can be easily dismantled and moved to another location, should the beneficiaries being resettled. The system was provided to the 13 families living in the target settlement and was installed by a local company with all components available on the Lebanese market. The system powers four LED lights ensuring indoor and security lighting (Fig. 4), and a small thermoelectric refrigerator (Fig. 5). The aim of this pilot was to explore the effectiveness of portable and flexible solutions for basic needs, such as lighting and food preservation.

According to the beneficiaries, the new electric system was preferred to the old one. They appreciated its reliability compared to the main grid, characterized by frequent and long-lasting blackouts and cutoffs.

Refrigerators were mainly used by the families to preserve different types of food, including vegetables and fruits (16\%), bread (30\%), and food leftovers (12\%). Qualitative surveys revealed that all the beneficiaries perceived an improvement in the means of food preservation after the introduction of the refrigerators. On the other hand, surveys also revealed that the potential of this technology (refrigerators) was not fully exploited by the users, due to both a limited availability of food to be preserved, and the unfamiliarity of people with this kind of devices. In particular, this was confirmed by the fact that, except for one case, the permanence of any foods in the refrigerator was very short (1.3 days in average, over a monitoring period of 7 months). Therefore, in this case the main finding was that specific capacity building of the 


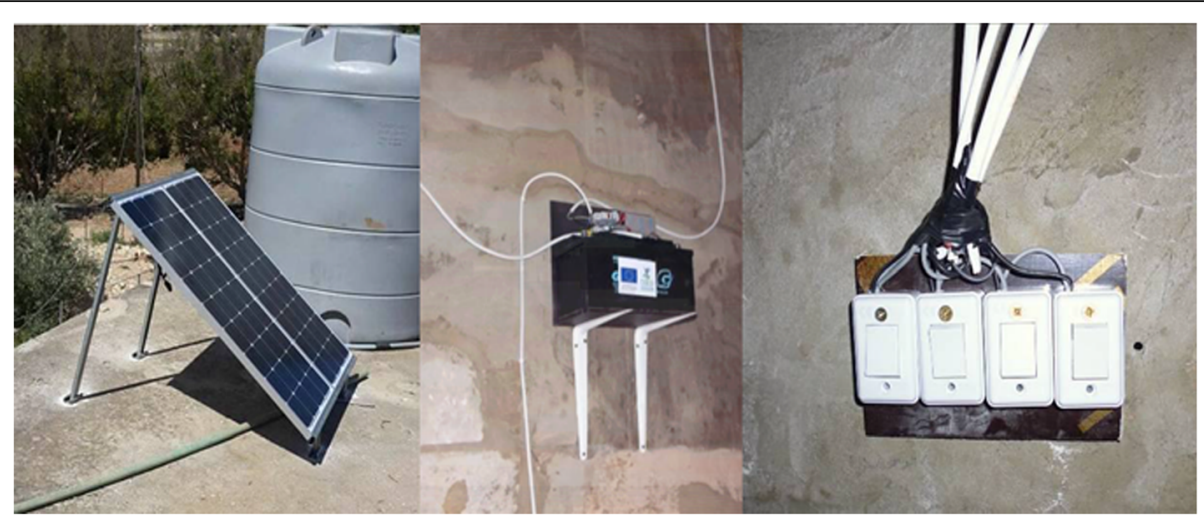

Fig. 4 Main components of the standalone PV system

beneficiaries is required for an effective utilization of new practices, such as food preservation through non-traditional systems. ${ }^{3}$

\section{Hybrid solar/wind power system with multi-compartment refrigerators (Lebanon)}

The proposed solution is a hybrid $\mathrm{P} V /$ wind micro-grid providing energy to seven community refrigerators. It was installed by a local company with components available on the Lebanese market.

The system integrates $3 \mathrm{~kW}$ of solar PV with a $2.5-\mathrm{kW}$ horizontal axis wind turbine, and a $25-\mathrm{kWh}$ battery bank. Refrigerators have a global capacity of $700 \mathrm{l}$ and are divided in eight compartments of about $90 \mathrm{l}$ each (Fig. 6). Each compartment is assigned to a single family, or shared between families with some parents in common, and is lockable with a personal key. Community refrigerators are placed in a common space and are designed to work in case of discontinuous power supply by

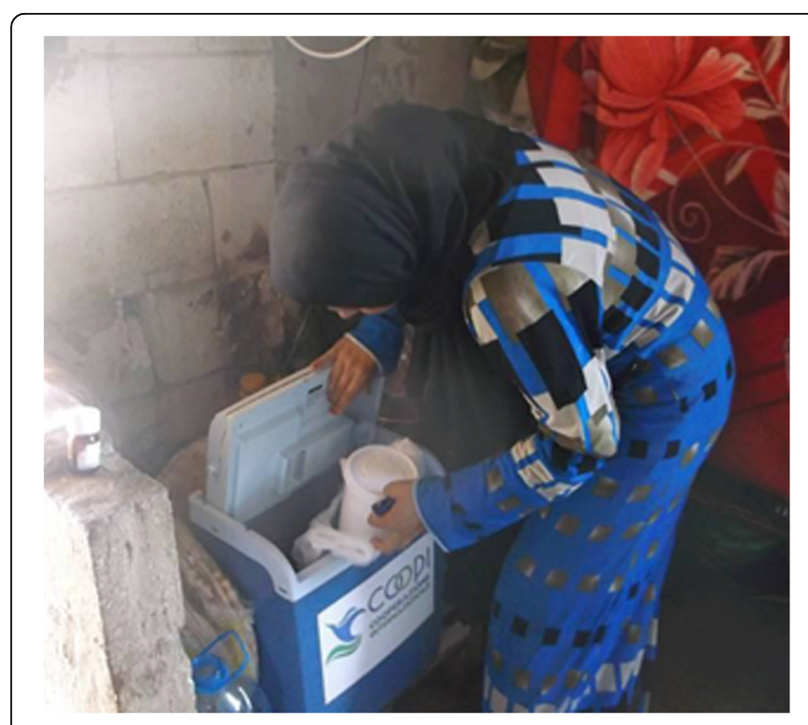

Fig. 5 The thermoelectric refrigerator in use integrating eutectic plates, which help maintaining a constant temperature in case of electricity shortage. The overall solution (micro-grid and refrigerators) was tested as an innovative system capable to provide reliable electricity supply and to ensure safe preservation of food in hard conditions by exploiting renewable energy sources and combining the benefits of a community installation (cost reduction and increased energy efficiency) with those of personal utilization.

Qualitative surveys were delivered to a sample of 30 families. Thanks to the new systems, $97 \%$ of respondents

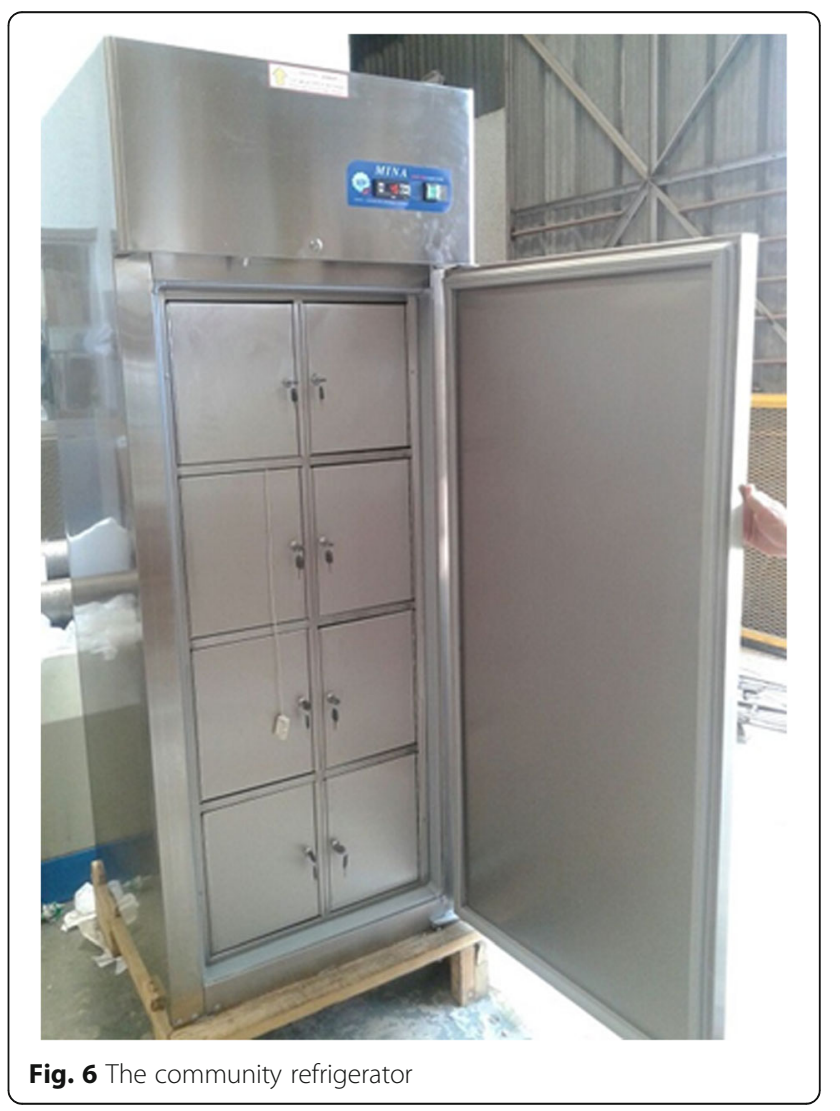


referred that they could better meet their energy-related needs. In particular, $80 \%$ of beneficiaries reported that the refrigerators allowed them to store food for a longer period in a safer and healthier way. Food leftovers could be preserved, to be consumed later on especially by women and children (Fig. 7). Some households also reported that the use of refrigerators changed the composition and frequency of grocery shopping (20\% of cases). In addition to qualitative data collection, sensors measuring the number of openings of the doors were installed in each refrigerator, to get a proxy measure of the rate of utilization. The results show that the frequency of utilization was about twice per day per family (Table 2, considering that each refrigerator was divided into eight compartments).

A critical point was given by the fact that the system was owned by a management committee chosen by the refugee community that was changed many times due to the high rate of mobility of the refugees. Also, the power system could only cover the very basic energy needs of the community, due to the huge number of households in the settlement. Moreover, the difficulties experienced during the procurement and installation of the systems due to the limited experience of local suppliers showed that materials and expertise in the field of complex renewable energy systems are not always locally available, nor sufficiently reliable.

\section{Comparison of improved cookstoves (CAR)}

In Central African Republic (CAR), two improved cooking stove (ICS) models were distributed and tested: a commercial model imported from Kenya was distributed to 70 families, and a locally made ICS to other 25 families $^{4}$ (Fig. 8). In this case, the aim was dual: on the one hand, the comparison between locally made and commercial solutions, in order to investigate differences in terms of performances, and on the other hand, to understand the different reactions of the beneficiaries to different designs and layouts of the same technology.

Both the ICS models were much appreciated by the beneficiaries, since they immediately noticed a strong reduction in fuel consumption, as well as in time for wood collection or money spent for fuel purchase. Fuel reduction was confirmed by quantitative data collection, which revealed a reduction of more than $50 \%$ of firewood consumption for both the commercial and the locally made stove, and a significant reduction of the time dedicated to fuel collection. For the case of the commercial ICS, a reduction of fuel expenditures of $41 \%{ }^{5}$ was also noticed, while it was not possible to get any significant conclusion for the case of the locally made ICS (Table 3).

On average, ICS were used more than twice per day by each household, confirming a shift from three-stone fire. Such results stimulated local entrepreneurship, and some private actors evaluated to start a local business for the construction of ICS.

It is interesting to notice that the beneficiaries considered the locally made model more robust, even if on the long-term the commercial model showed better performances in terms of durability. This fact shows how people experience can influence their perception and acceptance of a given technology. It is also interesting to underline that both ICS performed in a similar way in the field, even if the commercial model was supposed to be more efficient, based on laboratory tests. This fact gives evidence on the fact that users' behavior and practices influence the real performances of stoves in the field, thus results from laboratory tests should not be used as the only and most important parameter to select the best ICS model (Lombardi et al. 2017).

\section{Locally made solar refrigerator (SPARK model)}

The Solar Photovoltaic Adaptable Refrigeration Kit (SPARK) was designed by Politecnico di Milano to allow communities to assemble solar-powered refrigerators using locally available materials with a competitive price (Del Pero et al. 2015). Although SPARK was designed to be battery-free and to be equipped with a thermal storage in order to not require fuel, like sorption refrigerators, in SET4food project, the system was modified and tailored to increase its reliability. More in detail, in order to ensure continuous power supply during periods in which PV

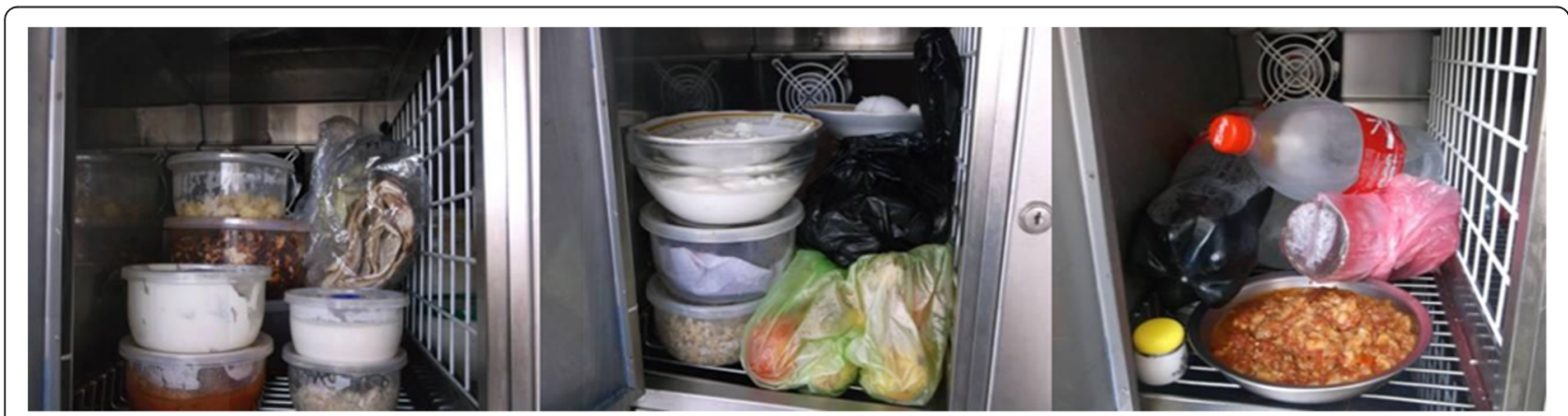

Fig. 7 Examples of preserved food by different families 
Table 2 Average daily openings of the refrigerators' doors

\begin{tabular}{llllllll}
\hline & Refrigerator 1 & Refrigerator 2 & Refrigerator 3 & Refrigerator 4 & Refrigerator 5 & Refrigerator 6 & Refrigerator 7 \\
\hline $\begin{array}{l}\text { Average daily openings } \\
\text { (over an 8-month period) }\end{array}$ & $8(4.85)$ & $15(10.35)$ & $16(8.52)$ & $18(12.05)$ & $12(6.33)$ & $15(9.37)$ & $26(17.19)$ \\
\hline
\end{tabular}

Standard deviation in brackets

system is unable to cover the entire electricity demand, the refrigeration group was connected to a battery group.

The electric and mechanical parts, i.e., a compressor (with a thermostat), a roll-bond evaporator pre-charged with refrigerant, and plug-in connectors for the refrigerant circuit, are commercial components provided in a compact kit that can be shipped almost everywhere, while the envelope and the compartments are locally constructed by using different materials. The photovoltaic panels are locally purchased.

The pilot aimed at testing a solution which couples the advantage of using local materials to the advantage of adopting reliable mechanical components. Moreover, since the envelope is locally made, it can be designed according to the specific needs and constrains. For example, the refrigerator can be divided into lockable compartments, so that each family can be assigned with one of them.

In order to test the solution, six refrigerators were assembled, with a 500-1 capacity and four lockable compartments each (Fig. 9).

Based on qualitative surveys among beneficiaries, the refrigerators helped in the preservation of vegetables (mainly carrots, onions, potatoes, sweet potatoes, tomatoes, egg plants, cabbage, leek, sweet pepper), fruits (mainly papaya, oranges, shadek-a sort of local grapefruit), water, and juices, thanks to their reliability compared to traditional refrigerators. The reliability of the system was also a leverage for small business activities. For example, one of the beneficiaries improved the trade of meat thanks to the better and cheaper means of preservation compared to buying ice every day.
On the other hand, the pilot showed that a lack of expertise in local manufacturing can represent a bottleneck in the construction of the envelope and in the overall assembly of the system.

\section{Supportive tools}

On the one hand, the proposal for a methodology, and the field testing of the methodology itself and of innovative technologies, contributed to limit the existing gap in terms of energy-related areas of intervention. In fact, as underlined in the introduction, the humanitarian response has in general focused only on the problem of cooking, thus excluding many other relevant issues, such as food preservation. On the other hand, the initial analysis also showed that there are few practical instruments such as tools and guidelines available for humanitarian workers. In most cases, humanitarian operators do not have solid knowledge of the energy problem and face important challenges in terms of time constraints, making decisions under pressure. Therefore, selected strategies do not always comply with the requirement of sustainability or consider most effective technologies. For this reason, there is a need to develop instruments to guide the definition of a solid energy strategy. SET4food tried to start facing such need by proposing a package with different tools.

\section{SET4food guidelines}

The Guidelines on sustainable energy technologies for food utilization in humanitarian contexts and informal settlements are the first tool developed during the project (Barbieri et al. 2015).

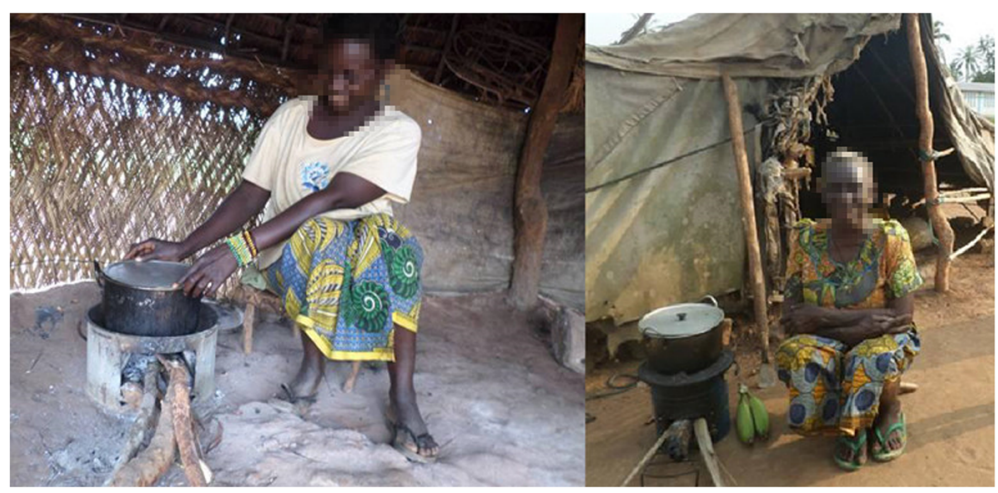

Fig. 8 Improved cooking stoves in CAR 
Table 3 Savings due to ICS distribution in CAR

\begin{tabular}{lcc}
\hline & Commercial ICS & Locally made ICS \\
\hline Wood consumption & $-63 \%^{* * *}(16 \%)$ & $-61 \%^{* * *}(20 \%)$ \\
Time to collect wood & $-54 \%^{* * *}(35 \%)$ & $-64 \%^{* * *}(33 \%)$ \\
Fuel expenditure & $-41 \%^{* *}(59 \%)$ & Not significant \\
\hline $\begin{array}{l}\text { Standard deviation in brackets } \\
\text { **, and }{ }^{* * *} \text { indicate significance at the } 90,95, \text { and } 99, \text { respectively }\end{array}$
\end{tabular}

The Guidelines support the process of identification of the most appropriate energy technologies and have been written in order to describe the main characteristics of the different technology options, considering that in most cases field operators do not have a strong technical background.

The guidelines provide both technical and non-technical information, starting from a list of different needs and corresponding energy solutions for food utilization, grouped within four main categories:

- Technologies and fuels for cooking (e.g., improved biomass cookstoves, biogas stoves, electric stoves);

- Technologies for food preservation (e.g., solar refrigerators, passive refrigerators, canning methods);

- Energy conversion systems for water pumping and purification (e.g., PV pumps, ultraviolet lamps, water filters);

- Modular integrated renewable energy systems (IRES) for electric supply.

Within each category, the main text provides a description of existing layouts and models of each group of technologies, as well as indications on the efficiency and the functioning principles. Figures and schemes clarify key issues, illustrating the main components or the physical principles of functioning.

When further details are needed, additional technical sheets describe the characteristics of each technology and give indications about manufacturing, proper utilization, operation and maintenance, and other practical recommendations.
The guidelines are open access and have been released in English, French, and Spanish in order to maximize their diffusion in all the main intervention areas. The document raised a great interest, as it is evidenced by more than 600 visualizations and downloads.

\section{Decision support system}

The Decision Support System (DSS) is an online interactive tool supporting the identification of appropriate energy technologies, based on the specific context in which the user is trying to operate. It helps in the preliminary selection of technologies for food preparation and preservation, and other related issues such as electricity for different uses, according to a number of parameters, such as geographical location, local climate, available resources, and other information provided by the user. The tool is composed by a "module 0 " that allows to enable or inhibit access to core modules based on a set of questions to which the user is required to answer. Core modules are five, directly referring to the different sections of the guidelines: (i) cooking, (ii) food preservation, (iii) power generation, (iv) water pumping, and (v) water treatment.

Within each module, specific questions guide the user in providing the requested information. Based on the answers, a set of indicators is evaluated. Such indicators are combined together, and the result is given in the form of a ranking of the different technologies, taking into account technological, economic, social, and environmental aspects. An example of ranking for the case of cooking is given in Fig. 10.

The DSS is available online in English, French, and Spanish, with a user manual (Barbieri et al. 2016).

\section{Monitoring, evaluation, and impact assessment package}

Based on the work and studies carried out during the first phase of the project, the lack of documentation on effective monitoring, evaluation, and impact assessment of energy-related interventions emerged as a further



Fig. 9 SPARK refrigerators in Haiti 


\section{Decision Support System}

\begin{tabular}{|l|l|l|l|}
\hline cooking & water treatment pumping & food preservation \\
\hline
\end{tabular}

\section{COOKING MODULE}

\section{Final ranking}

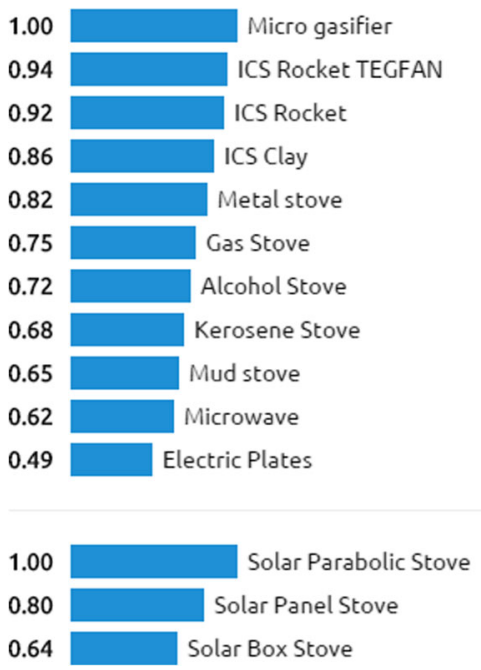

Fig. 10 Example of final ranking (cooking module)

critical element. As a consequence of such gap, few quantitative data and evidence-based results are exchanged at the end of most projects (Barbieri et al. 2017).

For this reason, a package for $M \& E$ and impact evaluation was proposed during SET4food phase 2, composed by the $M \& E$ framework, and the impact evaluation framework tool.

To be effective, monitoring and evaluation (M\&E) should not only assess the achievement of expected objectives, but also monitor recipients' roles within the various steps of the project. From this perspective, the approach proposed by SET4food combines the logical framework approach and the sustainable livelihoods framework (Kollmair and Gamper 2002). While the first represents a widely used tool for assessing the achievements of the project steps, the integration with the latter allows considerations of the importance of the recipients' roles within the project activities in order to induce targeted changes in livelihoods. From this viewpoint, the new integrated $M \& E$ approach helps to set up an effective set of indicators to perform a people-oriented evaluation of the project aside from a mere evaluation of the completion of the project phases (Politecnico di Milano 2018).

The impact evaluation framework (IEF) is further proposed as a complementary practical tool implemented in Microsoft Excel@. The tool aims at enabling the understanding of performance and impact of energy projects. A specific version has been developed in the framework of SET4food, including a set of indicators and recommendations specific to the humanitarian context. $^{6}$

The tool allows to measure the effects that a project has on the local livelihoods, assessed in terms of target community's five capitals: natural, physical, human, social, and financial. The model at the basis of the tool is an original re-elaboration of the "Sustainable Livelihoods Framework" (Kollmair and Gamper 2002; Colombo et al. 2018).

The tool can be applied to get an ex-post analysis, assessing already completed projects by comparing the measure of capitals in the baseline situation with the changes brought by the project and assessed at its end (Fig. 11). It has also been used for ex-ante analysis, at an appraisal phase, during the selection process among possible project alternatives. In this case the result is the expected impact of the intervention.

\section{Networking and knowledge sharing}

Outcomes and results of the project have been disseminated through the website and a YouTube channel, as well as public events, but the most important action as regards dissemination and knowledge sharing is represented by the design and launch of ENERGYCoP. 




Fig. 11 Example of graphical output from the IEF tool

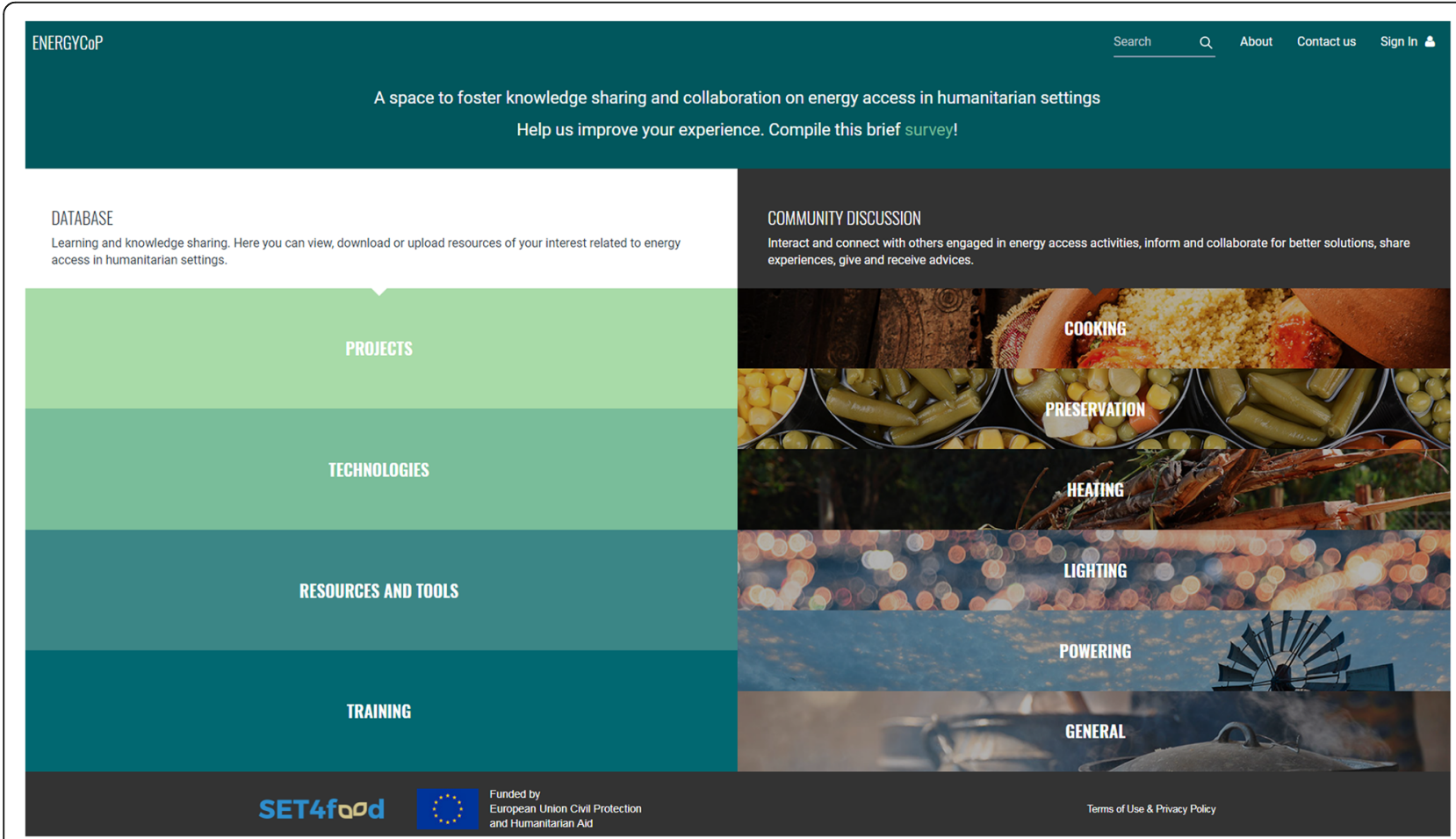

Fig. 12 The ENERGYCoP homepage 
ENERGYCoP is an online global, not-for-profit community of practice launched in the framework of SET4food second phase (Fig. 12), managed by SAFE. Its purpose is to facilitate information sharing and increase collaboration among a diverse network of stakeholders who are engaged in providing Safe Access to Fuel and Energy (SAFE) to crisis-affected people, such as refugees, IDPs, and those affected by disaster caused by natural hazards. Within this community of practice, every individual and organization working on issues related to energy access and energy technologies in humanitarian settings can access resources, connect with partners, and contribute to ongoing discussions on various topics.

ENERGYCoP is designed to be an interactive platform with an open-knowledge approach that enables users to search for projects, technologies, tools, and resources related to energy access in humanitarian settings, or to share materials that are considered valuable for the community. It allows to pose questions, ask for advice, or share experiences and best practices with the other members.

\section{Achieved results and way forward}

Despite an increasing number of displaced people in the world, energy has not been considered as a major topic in people displacement yet. This fact in many cases has exacerbated many negative aspects related to emergency and post-emergency situations, including in particular those related to food utilization. Such situation proves that new solutions are required, not only in terms of technology development, innovation, or adaptation, but also in terms of decision making, sensitization, training, and support to humanitarian actors. The SET4food project phase 1 and phase 2 contributed to tackle the main criticalities emerged in the humanitarian sector that are associated to energy.

Global awareness and knowledge of energy relevance has been increased, and the legacy of the project is an online open access for humanitarian officers, students, and operators in the field. Moreover, the project delivered in-presence trainings. The SET4food online and in-presence training activities reached more than 300 people on different levels, which represent a considerable result for the project itself, but just a first step in the overall sector.

A methodology for energy planning, technology transfer, and adaptation in humanitarian or critical contexts was drafted and then applied to different pilots during the first phase of the project to enhance the capacity in planning, implementation, monitoring, and evaluation. The application of the methodology in the field permitted its enhancement and revision, in order to focus on the most critical elements that can drive the success or failure of energy interventions, and to identify some key lessons learned. The field experiences confirmed the relevance of a holistic approach and suggested that energy is also a key element in the shift from emergency to post-emergency and development. Looking at the technical solutions themselves, the pilots clearly showed that the appropriateness of a technology strictly depends on local conditions and requirements. For this reason, the assessment of the context is very important, and all the relevant information should be considered and properly analyzed. Another factor showing high relevance for the success of field interventions is the setup of a strong monitoring system. As an example, the utilization of remote monitoring devices in the SET4food pilots contributed to identify faults, blackouts, or improper utilization of the systems and hence to carry out prompt corrective actions. In fact, a strong monitoring system helps in understanding or avoiding people's complaints and reduces the risks of ineffective actions. The technological factor itself plays a relevant but not unique role, while other factors such as tradition and people's perception can be as much determinant on the adoption of a given solution.

Such considerations also draw to the conclusion that the humanitarian sector should move more and more towards a new way of project formulation, based on a holistic and multidisciplinary approach. In order to face such challenges, in the second phase of the project, the supportive package of tools was enriched including a monitoring, evaluation, and impact assessment package for supporting project manager. It aims at helping in the definition and implementation of effective energy strategies, starting from the consideration that humanitarian actors in general do not have a specific background on energy issues. Such tools have received a quite positive response so far, which confirms their positive contribution to the sector.

Lastly, it is clear that projects such as SET4food will gain a much wider impact if a coordinated action of all the involved organizations and relevant initiatives is put in place. From this perspective, the launch of ENERGY$\mathrm{CoP}$ represents an important footstep on the way of a more coordinated and collaborative approach to energy in critical settings. As a matter of facts, ENERGYCoP capitalizes and collects not only the results and tools from SET4food, but also all the different experiences and capabilities from other initiatives regarding energy in humanitarian settings. Thus, the platform may enable a shift from a traditional "technological transfer" approach to a more participative one, including co-design and technological cooperation activated by a knowledge sharing mechanism.

Thanks to the results achieved so far, the SET4food action has joined a wider movement which includes other important initiatives such as the Moving Energy 
Initiative and the SAFE working group, on the way towards a global strategy for the provision of sustainable energy solutions in critical contexts. The launch of such a movement confirms the strong importance of a multidisciplinary and multi-stakeholder approach, where academia, NGOs, international organizations, and the private sector can join their efforts in an effective way to develop and propose effective strategies and solutions, not only looking at short-term benefits, but also at long-lasting impacts.

\section{Endnotes}

${ }^{1}$ http://energycop.safefuelandenergy.org

${ }^{2}$ The course is available in English, French, and Spanish and can be accessed through the project's website: www.set4food.org

${ }^{3}$ For further details on this and the next solution, see (Aste et al. 2016).

${ }^{4}$ Reported results are based on a monitored sample of 25 and 15 families respectively for the case of the commercial and locally made stove.

${ }^{5}$ In some cases fuel was purchased from other refugees, while in others it was directly collected by final users.

${ }^{6}$ Downloadable at http://bit.ly/2EITkTu

\section{Additional file}

Additional file 1: Summary table of all the implemented solutions. (DOCX $20 \mathrm{~kb}$ )

\section{Abbreviations \\ AC: Alternating current; CAR: Central African Republic; DC: Direct current; DSS: Decision Support System; ENERGYCoP: Energy Community of Practices; HQ: Headquarter; ICS: Improved cooking stove; IDPs: Internally displaced persons; IEF: Impact evaluation framework; M\&E: Monitoring and evaluation; MEl: Moving Energy Initiative; OCHA: Office for the Coordination of Humanitarian Affairs; SAFE: Safe Access to Fuel and Energy; SET4food: Sustainable Energy Technologies for food security; SPARK: Solar Photovoltaic Adaptable Refrigeration Kit}

\section{Acknowledgements}

The authors would like to thank all the staff of COOPI - Cooperazione Internazionale, and of Politecnico di Milano involved in the project. In particular, they would like to express their sincere gratitude to Marco Caniato for his unique contribution to the first phase of the project, and Cristina Sonzogni as regards the second phase, as well as to all the colleagues of the Department of Energy and the Department of Architecture, Built Environment and Construction Engineering, that dedicated their time and efforts to different activities of the project.

\section{Funding}

The SET4food project is funded by the European Commission's Humanitarian Aid and Civil Protection Department (ECHO) and co-funded by the project partners. The SET4food phase 1 partners were COOPI - Cooperazione Internazionale as the leading agency, in partnership with Politecnico di Milano, and Fondazione Politecnico di Milano. The SET4food phase 2 partners are COOPI - Cooperazione Internazionale as the leading agency, in partnership with Politecnico di Milano, and three co-chairs of the SAFE Working Group: Global Alliance for Clean Cookstoves (GACC), World Food Programme (WFP) and Food and Agriculture Organization (FAO).

\section{Availability of data and materials}

Please contact author for data requests.

\section{Authors' contributions}

JB coordinated the project activities for Politecnico di Milano and wrote the first draft of this work. FL helped in the coordination of the project with a special focus on activities related to food preservation and added to the second draft of this work. EC was scientifically responsible for the project and lunched the idea of the energy planning methodology and of some of the supportive tools, and added to the second draft of this work.

\section{Competing interests}

The authors declare that they have no competing interests.

\section{Author details}

${ }^{1}$ Department of Energy, Politecnico di Milano, Milan, Italy. ${ }^{2}$ Department of Architecture, Built Environment and Construction Engineering, Politecnico di Milano, Milan, Italy.

Received: 5 March 2018 Accepted: 12 June 2018

Published online: 01 July 2018

\section{References}

Aste, N., Barbieri, J. et al. 2017. Innovative energy solutions for improving food preservation in humanitarian contexts: a case study from informal refugees settlements in Lebanon. Sustainable Energy Technol Assess 22. https://doi. org/10.1016/.seta.2017.02.009.

Aste, N., Del Pero, C. \& Leonforte, F., 2016. Active refrigeration technologies for food preservation in humanitarian context - a review. Sustainable Energy Technologies and Assessments. 2017;22:150-60. ISSN 2213-1388, https://doi. org/10.1016/j.seta.2017.02.014.

Barbieri J, Riva F, Colombo E (2017) Cooking in refugee camps and informal settlements: a review of available technologies and impacts on the socioeconomic and environmental perspective. Sustainable Energy Technol Assess 22:194-207 Available at: https://doi.org/10.1016/j.seta.2017.02.007

Barbieri J et al (2015) Guidelines on sustainable energy technologies for food utilization in humanitarian contexts and informal settlements. In: Barbieri J, Colombo E (eds) . Department of Energy, Politecnico di Milano, Milan Available at: http://bit.ly/2Exb7NZ

Barbieri, J. et al. 2016. Handbook on how to use the SET4food DSS. Available at: http://bit.ly/2Ghij19

Bellanca, R., 2014. Sustainable energy provision among displaced populations: policy and practice, London, UK

Callaghy K, Riddley K (2018) Planning and Coordination - Emergency and Protracted Crises. In: Concept and background notes from the "Energy for Displaced People: A Global Plan of Action for Sustainable Energy Solutions in Situations of Displacement" conference. Global Alliance for Clean Cookstoves, Berlin Available at: http://bit.ly/2orq1 dH

Colombo E et al (2018) An impact evaluation framework based on sustainable livelihoods for energy development projects: an application to Ethiopia. Energy Res Soc Sci 39:78-92 Available at: http://linkinghub.elsevier.com/ retrieve/pii/S2214629617303791

Del Pero C et al (2015) Feasibility study of a solar photovoltaic adaptable refrigeration kit for remote areas in developing countries. In: 2015 International Conference on Clean Electrical Power (ICCEP), pp 701-708

$F A O$, 2015. Ensuring safe access to energy for all

Gunning, R., 2014. The current state of sustainable energy provision for displaced populations: an analysis, London, UK

Jenks A, Fohgrub T, Callaghy K (2018) Technical Expertise, Capacity Building and Training. In: Concept and background notes from the "Energy for Displaced People: A Global Plan of Action for Sustainable Energy Solutions in Situations of Displacement" conference. UNITAR, Berlin Available at: http://bitlly/ 2orq1dH

Kollmair, M. \& Gamper, S., 2002. The sustainable livelihoods approach, Zurich Lahn, G. \& Grafham, O. 2015 Heat, light and power for refugees. Saving Lives, Reducing Costs., London. Available at: http://www.chathamhouse.org/sites/ default/files/publications/research/2015-11-17-heat-light-power-refugeeslahn-grafham-final.pdf

Lombardi F et al (2017) Biomass and bioenergy laboratory protocols for testing of improved cooking stoves ( ICSs ): a review of state-of-the-art and further 
developments. Biomass Bioenergy 98:321-335 Available at: https://doi.org/10. 1016/.j.biombioe.2017.02.005

Lyytinen E (2009) Household energy in refugee and IDP camps: challenges and solutions for UNHCR. In: New Issues in Refugee Research, vol 172, p 20

Available at: http://www.unhcr.org/research/working/4a1d2f422/householdenergy-refugee-idp-camps-challenges-solutions-unhcr-eveliina.html

OCHA, 2010. Energy security and humanitarian action: key emerging trends and challenges, Geneva

OCHA, 2017. Global humanitarian overview 2018. A consolidated appeal to support people affected by disaster and conflict. Available at: https:/www. unocha.org/sites/unocha/files/GHO2018.PDF

Politecnico di Milano (2018) Monitoring \& evaluation an integrated framework. Politecnico di Milano, Milano Available at: http://bit.ly/2ByAYIO

Puri J et al (2017) Can rigorous impact evaluations improve humanitarian assistance? Journal of Development Effectiveness 9(4):519-542. https://doi. org/10.1080/19439342.2017.1388267

Rosemberg-Jansen S (2018) Data, evidence, monitoring and reporting on energy for displaced people. In: Concept and background notes from the "Energy for Displaced People: A Global Plan of Action for Sustainable Energy Solutions in Situations of Displacement" conference. Practical Action; University of Oxford, Berlin Available at: http://bit.ly/2orq1dH

SAFE, 2016. Energy access in humanitarian settings

Türk V et al (2015) UNHCR. In: The environment and climate change

UNHCR (2016) Global trends_forced displacement in 2015. Switzerland

Geneva Available at: https://reliefweb.int/sites/reliefweb.int/files/resources/ 576408cd7.pdf

WFP, 2015. Safe Access To Fuel and Energy (SAFE) 2015, Available at: www.wfp. org/safe

Wohlgemuth A, Mazumder S, Andreatta D (2009) Computational heat transfer analysis of the effect of skirts on the performance of third-world cookstoves. J Thermal Sci Eng Appl 1(4):41001 Available at: http:// thermalscienceapplication.asmedigitalcollection.asme.org/article. aspx?articleid=1469321. [Accessed 31 July 2013]

\section{Submit your manuscript to a SpringerOpen ${ }^{\circ}$ journal and benefit from:}

- Convenient online submission

Rigorous peer review

- Open access: articles freely available online

- High visibility within the field

- Retaining the copyright to your article 